Shadows over accreditation in higher education: some quantitative evidence

Martino Andreani

Università Cattolica del Sacro Cuore, Milan, Italy

Daniel Russo

Department of Human Sciences, Territory and Innovation, Università degli Studi dell'Insubria, Varese, Italy

Silvia Salini

Department of Economics, Management and Quantitative Methods, Università degli Studi di Milano, Milan, Italy.

Matteo Turri, Corresponding Author

Department of Economics, Management and Quantitative Methods, Università degli Studidi Milano-matteo.turri@unimi.it (corresponding author) 


\section{Shadows over accreditation in higher education: some quantitative evidence}

Accreditation systems in Higher Education are widespread both in the US and in Europe. However, numerous reservations have appeared in the literature about whether these systems can comprehend and represent the quality of university courses. This study sets out to contribute to this debate by discussing whether the results of the recent university teaching accreditation system in Italy are influenced by the characteristics of degree programmes, their performance and the characteristics of incoming students. Whilst addressing this research question this paper intents above all to give a methodological contribution by proposing an evidence-based approach that tackles the limits found in the literature in relation to university accreditation and quality assurance

Keywords: Accreditation; Quality Assurance in Higher Education; Evidence-based approach; Italian Quality Assurance; Performance Indicators. 


\section{Introduction}

The function of national accreditation systems is to ascertain the existence of qualitative requirements through an evaluation process. Accreditation systems are particularly widespread when providers are not the public bodies that are responsible for the costs of services and when providers are highly autonomous from the regulating/financing body. Health and Education are two of the sectors where this mechanism is particularly common. There may be several aims of adopting an accreditation system but the main purposes can be summarised as follows: (i) to ascertain that a service is provided in compliance with previously established standards (also to facilitate competitive mechanisms and/or cooperation among institutions); (ii) to ensure that public resources are used properly; (iii) to encourage accredited institutions to improve their services.

In the field of Higher Education in US and Europe, the dissemination of accreditation systems is significant despite their differences. In particular, what differs is the role that national governments play in accreditation systems. In the US, voluntary, non-governmental, non-profit bodies have spread as accreditation bodies since the end of $19^{\text {th }}$ century (Stensaker 2011). In this respect, Quality Assurance (QA) provides a self-regulatory activity organised by 80 non-governmental associations (Rhoades and Sporn 2002; Wilkerson 2017). The link between accreditation and federal government became stronger after the Second World War (Flood and Roberts 2017), when the government enacted benefit programmes (in the form of grants and loans) to facilitate the reintegration of war veterans into society only in universities and colleges that had been accredited by an agency recognised by the federal government in order to ensure proper use of federal funding. However, accreditation is still voluntary in the US even though the possibility of obtaining federal funds makes it almost compulsory. 
The spread of accreditation in Western Europe is more recent like everywhere else (Cheng 2015). In Europe the first national QA programmes were implemented in the UK and the Netherlands (Van Vught 1988). The dissemination of QA programmes is associated with the increased autonomy of universities and the subsequent need to find a way to steer them at the distance (Neave and Van Vught 1991), so that the national government (which mostly remains the main financial contributor) can steer the university systems in new ways. Accreditation systems meet the government's need to have a mechanism to control and guide the activities of universities that may be less explicit and more socially acceptable than direct control (Vidovich 2002).

Another element encouraging the spread of accreditation and QA systems in Europe is associated with the Bologna Process. In the process of establishing a European Higher Education Area (EHEA), the need of common elements at the European level whilst keeping national education systems autonomous translated into the fact that the acceding countries were requested to have national accreditation systems (Van der Wende \& Westerheijden 2001; Huisman and Westerheijden 2010). For this purpose, the European Network of Quality Assurance Agencies (ENQA) was firstly established and then the European Standards and Guidelines (ESG) were drafted to provide the requirements that the national QA systems have to adopt in relation to the internal quality assurance of universities and the external quality assurance of national agencies (Sin et al. 2017). Another step forward in this direction was the creation of the European Quality Assurance Register for Higher Education (EQAR) for the QA agencies adopting the ESG.

In reality, the theoretical notion of accreditation in the Higher Education sector is rather vague (Erichsen 1999; Sursock 2000; Haakstad 2001; Schwarz and Westerheijden 2004). For the purposes of this paper, accreditation is meant as a national 
QA programme that has an impact on universities and degree programmes in terms of recognition by the national government and, ultimately, ability to operate. The final stage of the accreditation process consists in a site visit of a pool of evaluation experts within the academia (academic peers) that is in charge of verifying whether a university has a series of qualitative standards in relation to a specific degree programmes or the entire university; the accreditation is then issued by a supervisory body following a formal verification and assessment procedure (in this paper QA is intended in a broader sense including all evaluation activities). The definition used in this paper is intended to exclude from the analysis international or discipline-based accreditation procedures, thus focusing on national level accreditation.

The difficulty of defining accreditation is also linked to the large number of meanings that it can assume in university systems, both in terms of functions and in terms of political/bureaucratic processes included in the spread of accreditation. With regard to functions, Jeliazkova and Westerheijen (2002) identify incremental phases of the development of quality assurance systems at a national level, by highlighting how the first phase is aimed at verifying educational standards, the second at verifying the efficiency of an institution, the third at promoting innovation, the fourth is focused on stimulating the culture of quality, and the final phase is focused on the knowledge and skills of graduates as an indicator of performance of the curricula. In relation to the political and bureaucratic level, Stensaker (2011) highlights how accreditation can be linked, among other things, to consumer protection in the market, to increased influence of administrative and managerial functions on teaching and to networked governance.

Despite the different paths taken by the US and Europe, a certain vagueness in defining it and the multiple aspects linked to it, there is a leading theme throughout 
these accreditation processes: the debate on whether these systems can really lead to and improve the quality of Higher Education (Newton 2013; Cardoso et al. 2016).

This is not only an unresolved debate but also a methodological gap since the field of measuring the effects of QA in higher education is still under-theorised and under-researched, the spectrum of the methodologies that can be used has hardly been investigated; moreover, little attention has been paid to students' experiences (Newton 2013; Leiber et al. 2015).

This paper sets out to contribute to this debate by discussing how accreditation systems can provide a faithful and robust representation of the pre-established standards and, more specifically, how the outcome of the ad hoc accreditation procedures is influenced by the characteristics of degree programmes and by sue performance. Italy, the latest Western European country to launch a broad accreditation programme of universities and curricula in 2013 (Turri 2014), is the case study of this paper. In particular, the Italian case gives access both to the data on the results of the accreditation process and to the data on the characteristics of degree programmes.

The purpose of this paper is two-fold. First of all, it is methodological; usually, although the literature discusses limits and failures of accreditation systems, the analysis is often based on anecdotal evidence or without evidence-based data on the relationship between teaching process and accreditation results. Conversely, this paper explores this relationship by analysing to what extent and how the outcomes of the accreditation process are linked to the inherent characteristics and performance of degree programmes. Secondly, although there are a few limits that will be explained in the Data and Methods section, the analysis here conducted focuses on the fact that the results of the accreditation process in Italy are influenced by the characteristics of degree programmes, their performance and the characteristics of the incoming students 


\section{All that glitters is not gold: shadows of the accreditation systems}

The theory analyses accreditation systems from multiple viewpoints that are partly opposing and partly converging. Two among various fields of research are particularly significant:

- the theories of neo-institutional sociology; and

- the studies focusing on the spread of the so-called New Public Management (NPM) and the limits of this view.

New Institutionalism, based on environmental drives and organisational behaviour (DiMaggio and Powell 1983), emphasises that accreditation systems are aimed at reducing the uncertainty structurally affecting the Higher Education sector. Without unambiguous and recognised metrics of the quality and effectiveness of education, such systems act as quality stamps (Cret 2011). In this view, accreditation and, in general, QA processes are interpreted as a case of institutional isomorphism. In New Institutionalism there is a special focus on QA mechanisms as a case of state delegation of power. In this context, there is a risk that QA systems respond to a mere need of external legitimacy and that their internal management is conversely associated with real organisational processes, so much so that their organisational potential is decreased or even abolished (Meyer et al. 1991; Power 1997). Therefore, universities create a buffer interface with external accreditation bodies to ensure the legitimacy of processes (Power 1997). 
NPM, which is inspired by experiences and practices of the for-profit sector to improve the public sector (Hood 1995; Deem 1998) has the improvement of accountability and evaluation systems as one of its main operational implications (Talib 2003; Ferlie et al. 2008; Pollitt 2009; Frølich and Caspersen 2015). In other words, the goal of NPM, also through the use of tools such as accreditation, is to combine the benefits of trade in terms of efficiency and consumer freedom with the benefits of the State in terms of solidarity and rights of access to services (Van de Bovenkamp et al. 2013). In the context of HE, accreditation systems constitute, in particular, a tool aimed at assisting the transition from a state control model to a state supervisory model (Meek and Davies 2009). Whilst the government's traditional intervention mechanisms were hierarchy and authority (by means of the law), following the NPM reforms the State adopts new tools such as standards and intermediary bodies in charge of the quality of services (Westerheijden 2007).

However, unlike private undertakings (Thomas 2004), in public organisations, such as typically universities in Europe, the definition of the expected outcome is particularly complicated. NPM postulates that it is always possible to track the causal and rational link leading to certain factors, generating desired outputs and outcomes (Noman 2008; Van Dooren et al. 2010). This assumption clashes with the nature of the outputs of the public sector (Behn 2003; Noordegraaf and Abma 2003), such as Higher Education. Thus, there is a wide range of literature criticising the effectiveness of these principles and models, by highlighting a growing gap between theory and practice in evaluation mechanisms (Perry et al. 2009; Diefenbach 2009). There is a risk that accreditation systems may increase administrative requirements, but their ability to improve services effectively may not be so evident (Pollitt and Bouckaert 2004). For 
these reasons, accreditation and QA systems are more vulnerable to the above mentioned isomorphism.

In relation to the specific features of Higher Education, in addition to the two above mentioned fields of research, it should be added that the study of accreditation systems must take into account the specific organisational aspects of universities.

According to Clark (1983), universities are characterised by a double-structured organisation with disciplinary and institutional levels. Becher (1989) points out that the disciplinary components, the so-called "Academic tribes", show marked differences in relation to culture, practices and values. Thus, convergent disciplines, such as Medicine, follow shared and uniform practices and rules and tightly control their "territories". Divergent disciplines, such as the Humanities, are loosely interrelated and their boundary work, concerning both intra- and interdisciplinary boundaries, is weak (Becher 1989).

In connection with the above mentioned organisational peculiarities, various authors highlight how disciplines influence not only the implementation but also the impact of QA systems (Canning 2005; Lomas 2007; Haapakorpi 2011).

Despite the differences in viewpoints, there is a consensus in the literature that the spread of accreditation and QA systems in universities may have limitations.

The 2015 white paper on accreditation of the US Senate "Higher Education Accreditation Concepts and Proposals" openly states that "accreditation has not always produced or improved educational quality" (p.3), but also "accreditation can inhibit innovation and competition" (p.5) and "accreditation can be costly, burdensome and inefficient" (p.8).

Although accreditation systems were implemented to ensure the quality of teaching and to encourage improvements, there are few studies discussing the link 
between external QA systems and improved teaching and learning (Stensaker 2011; Rosa and Amaral 2012). Various authors identify a link between external QA and internal managerial and organisational processes obtaining an advantage in terms of strengthening; however, there is still little evidence a-bout their real ability to impact on teaching and learning, which is ultimately the students' direct and concrete experience (Westerheijden, Hulpiau, and Waetens 2007; Stensaker 2008; Stensaker 2014; Cardoso et al. 2016). It is no coincidence that the literature is focusing on whether QA has moved away from the core academic activities and has become a mostly bureaucratic and mainly compliance-oriented process (Harvey 2005; Harvey and Newton 2004 and 2007; Ratcliff 2003; Morley 2003; Harvey 2016). Huisman and Westerheijden (2010) state that internal QA systems in Europe could be a good example of decoupling, as described by Power (1997), i.e. a buffer complying with the requirements of external evaluation bodies by creating verifiable performance measures that are unrelated with real organisational processes. As Harvey and Williams state $(2010$, p.107) "the link between external processes, internal processes, and improvements in teaching and learning seems to be tenuous and patchy".

Moreover, the majority of studies on the impact of QA are generally anecdotal and often based on no empirical evidence (Harvey 2006; Shah 2013; Shah and Stanford, 2013). The only exceptions to this are a few studies collecting the opinions of the actors involved on the benefits of QA systems (e.g. Stensaker 1997 and 2011; Shah 2013, Cartwright 2007; Veiga et al. 2013; Cardoso et al. 2016).

\section{Italy's degree programme accreditation system}

The Italian university system is one the most extensive in Europe with over 1.6 million enrolled students, over 300,000 graduates every year and 90 universities, 61 of 
which are public universities and 29 of which are private universities (11 of them are online universities). Only since 2013 the Italian universities have adopted an accreditation system for institutions and degree programmes (Ministerial Decree no. 47 of 30/01/2013). The QA model called AVA (self-evaluation, periodic evaluation and accreditation) is explicitly inspired by ESG. Although the first national accreditation system in Italy took place in 2013 , some quality assurance measures had already been implemented at national level in the past (Rebora and Turri 2011). At the disciplinary level, in Engineering degree programmes the Conference of Engineering Deans implemented an accreditation system, which was later integrated in the European system EUR-ACE (EURopean ACcredited Engineer), and a sector-based evaluation agency called QUACING (agency for quality certification).

At national level, on the basis of the previous experiences developed in the accreditation of engineering courses, CRUI (Conference of the Rectors of the Italian Universities) tried to promote a process to accredit degree programmes on a voluntary basis; this accreditation system was terminated when the originally granted public funds were exhausted.

The last exercises before AVA, at the national level, the Ministry promoted a system to verify compliance with certain minimum quantitative requirements (essentially based on the ratio of students/teachers) to authorise universities to create new degree programmes. The procedure had no connection to ESG and included no onsite visits.

The assumption behind the launch of AVA is a broad reform (Law 240/2010 called Gelmini Law) that has introduced major changes in the governance of Italian universities and imposed a reorganisation of the evaluation system in order to operate all teaching and research evaluation functions from the National Agency for the 
Evaluation of Universities and Research - ANVUR (for further details on the introduction of AVA procedures see Turri 2014 and Capano et al. 2016).

AVA consists of three stages: (1) internal QA carried out by each university at the level of both entire institution and individual degree programmes, (2) external QA conducted by ANVUR. and (3) a final accreditation stage after the Education Ministry has received the results of ANVUR's evaluation. In relation to the internal QA stage, every university is required to define its objectives and procedures for quality and improvement and to conduct an annual review for each degree programme. The internal QA process must comply with the quality standards established by ANVUR. The external QA process consists in that a CEV (Evaluation Expert Committee) appointed by ANVUR visits each university every 5 years. A CEV involves a variable number of experts according to the size of the university under examination: a chairperson, some QA experts (called System Experts), some experts in the subjects of the degree programmes (called Disciplinary Experts), and a number of evaluating students. The operations of CEV are designed in such a way that the role of the chair and the experts is crucial in their influence on the evaluation of requirements. In fact the evaluation documents are drawn up by the chair of CEV, who employs subcommittees coordinated by a QA expert to evaluate degree programmes.

At the end of the visit, a CEV issues an assessment of the compliance with the quality standards. These visits are aimed at examining the effectiveness of the internal QA system in the university and in about $10 \%$ of its degree programmes. An evaluation is given for each standard according to the following rating scale: A, excellent practice; B, approved; C, accepted with recommendation; D, not approved because of major critical issues. 
Once the individual evaluations are collected, a degree programme receives an overall evaluation based on the following scale: Fully Satisfactory, Satisfactory, Conditional, Not Accredited. The first two ratings result in a full accreditation; "Conditional" entails that the critical points highlighted in the visit must be addressed with corrective actions within a time limit; conversely, "Not accredited" leads to the termination of a degree programme.

Based on the evaluations obtained by the university and its individual degree programmes, ANVUR recommends whether the Ministry of Education should accredit a university. The evaluation report is finally issued. In general, although the Italian standards and the accreditation process are based on the ESG, they are influenced by the previous experiences in the field of Engineering as shown by the terminology used and by the fact that ANVUR involved the heads of QUACING in designing the standards and the first evaluations.

After ENQA had issued the new ESG (ESG 2015), ANVUR, also on the basis of a preliminary examination of the accreditation activities already underway, started a process to update the AVA system, which resulted in new guidelines issued in December 2016 and implemented in 2017 (Ministerial Decree no. 987 of 12/12/2016). According to ANVUR, the revision of the AVA system aims to (ANVUR, 2017):

- $\quad$ reduce the number of quality standards from 57 to 30 ;

- enhance the self-evaluation stage of universities before the visits;

- decrease the number of degree programmes to visit by maximising the QA of each university;

- create a stronger link between the outcomes of the QA process and the performance of a degree programme also by including student career indicators. 
The first results of the accreditations after the changes were available in 2018 and have therefore not been taken into account in this article (only the results of six universities have been published thus far).

\section{Data and methods}

One of the most challenging aspects of evidence-based studies is the difficulty of identifying a causal relationship between external QA and its impact on institutions, students and academic staff (Harvey, 2006). This study sets out to contribute to this debate by exploring the relationship between data, which were generated by the accreditation process, and the data normally available and used for monitoring degree programmes. Amongst these, variables related to the characteristics of the incoming students and the performance of the degree programmes in terms of retention and employability were considered. In addition to these data, other aspects were taken into account, i.e. the characteristics of the degree programme in terms of geographical location, disciplinary area, type of degree programme and the public or private nature of universities.

From 2014 to 2016, visits were carried out in 26 universities (5 of which were online universities), and 229 degree programmes (44 of which were in online universities) were evaluated. It is possible to analyse 21 universities and 185 degree programmes. Online universities were not taken into account in this analysis due to their organisational peculiarities and because the accreditation scheme involves partially different requirements for these institutions. The 185 degree programmes under examination range across all disciplines. Four of them were classified as "fully satisfactory", 54 "satisfactory", 126 "conditional" and only one degree programme was not accredited. 
Among the evaluating members of CEVs visiting universities, engineers are predominant and have key roles in the committees (Table 1; Table 2): an engineer was the chairperson in over $60 \%$ of the CEVs, whereas $40 \%$ of the system experts belonged to the engineering disciplinary field.

Table 1: ERC disciplinary area and type of institution of origin of the Chairperson* and System Experts* in CEVs

\begin{tabular}{|c|c|c|c|c|}
\hline ERC Macroareas & $\begin{array}{c}\text { CEV } \\
\text { chairs** }\end{array}$ & $\%$ of total & $\begin{array}{c}\text { System Experts } \\
\text { (from private } \\
\text { universities) }\end{array}$ & $\%$ of total \\
\hline $\begin{array}{l}\text { Physics and } \\
\text { Engineering (PE) }\end{array}$ & 16 & $76,19 \%$ & 30 & $52,63 \%$ \\
\hline whereof ENGINEERING & 13 & $61,90 \%$ & 24 & $42,11 \%$ \\
\hline Life Sciences (LS) & 2 & $9,52 \%$ & 5 & $8,77 \%$ \\
\hline $\begin{array}{l}\text { Social Sciences and } \\
\text { Humanities }\end{array}$ & 3 & $14,29 \%$ & $17(4)$ & $29,82 \%$ \\
\hline $\begin{array}{l}\text { Administrative and } \\
\text { technical staff }\end{array}$ & - & - & $5(2)$ & $8,77 \%$ \\
\hline Total & 21 & $100.00 \%$ & $57(6)$ & $100 \%$ \\
\hline
\end{tabular}

*a member of the committee may have carried out more than one visit and is therefore counted more than once

$* *$ None from private universities

Table 2: Origin (i.e. location of institution of origin) of CEV members*

\begin{tabular}{lcccc}
\hline Members* & Chairs & \% & System Experts & \% \\
\hline Northern Italy & 11 & $52.38 \%$ & 39 & $68.42 \%$ \\
Central Italy & 6 & $28.57 \%$ & 13 & $22.81 \%$ \\
Southern Italy & 4 & $19.05 \%$ & 5 & $8.77 \%$ \\
total & 21 & $100.00 \%$ & 57 & $100.00 \%$ \\
\hline
\end{tabular}

* a member of the committee may have carried out more than one visit and is therefore counted more than once

Every degree programme obtained an evaluation in the 15 standards listed in Table 3. Moreover, CEVs also gave every degree programme an overall evaluation summarising all 15 marks.

Table 3 - Quality Standards for Degree Programmes (ANVUR, 2014) 


\begin{tabular}{|c|c|c|}
\hline Standards & Item & Description \\
\hline \multicolumn{3}{|c|}{ Level of up-to-date educational offer } \\
\hline AQ5.A.1 & Consulted parties & $\begin{array}{l}\text { Representativeness of the national and } \\
\text { international social parties consulted with } \\
\text { respect to the effectiveness of the degree } \\
\text { programme }\end{array}$ \\
\hline AQ5.A.2 & Consultation mode & Adequacy of the timing of consultations \\
\hline AQ5.A.3 & Functions and competences & $\begin{array}{l}\text { Completeness and clarity in the definition } \\
\text { of career opportunities }\end{array}$ \\
\hline
\end{tabular}

AQ5.B.1 Entry-level required or Verification of the entry-level knowledge recommended knowledge required to succeed in a degree programme and verification of remedial actions

AQ5.B.2 Consistency between learning demand and learning results

AQ5.B.3 Consistency between teaching and learning Consistency between Intended Learning Outcomes and career opportunities

Consistency between teaching contents, methods and instruments and Intended results expected by degree Learning Outcomes

AQ5.B.4 Learning evaluation

Consistency between evaluation criteria and Intended Learning Outcomes

\section{Self-evaluation of degree programmes}

AQ5.C.1 Data analysis and issue identification

Ability to identify problems based on collected data and observations

AQ5.C.2 Identification of the causes of issues

AQ5.C.3 Solutions to address the identified issues

Ability to analyse the causes of issues

Effectiveness and adequacy of proposed solutions in terms of resources and accountability for their implementation

AQ5.C.4 Implementation and Adequate implementation of evaluation of the identified solutions improvements and monitoring their outcome

\section{Student satisfaction}

AQ5.D.1 Publicity of students' opinions on the degree programme

AQ5.D.2 Reports from students

Adequacy of the way in which students' opinions are publicised

Effective monitoring and evaluation of the Teachers -Students Joint Committee

AQ5.D.3 Acknowledgement of the students' opinions Ability of the course to receive the requests and observations of the students with consistent actions

\section{Career opportunities}

AQ5.E.1 Effectiveness of education Level of involvement of external stakeholders for the monitoring of the programme

AQ5.E.2 Employment support for Adequacy of the actions aimed at graduates improving the employability of students 
In order to answer the research question the evaluations of all 173 degree programmes for each quality requirement by CEVs were analysed in relation to the number of programmes examined is 173 and not 185 due to missing values in the variables under examination, in particular employment rate and percentage of students graduating within the prescribed duration of degree programmes):

- $\quad$ programme type (Bachelor's Degree, Master's Degree, Single-Cycle Degree);

- location of the universities (North, Centre, South);

- $\quad$ specific ERC macro-area (Physics and Engineering - PE; Social Sciences and Humanities - SH, Life Sciences - LS);

- the public or private nature of the universities;

- two input indicators that give a representation of the characteristics of the incoming students according to their final grade and the type of secondary school (theoretical or technical/vocational) since, for historical reasons, in Italy there are three types of secondary schools, subsequently divided into further specialisations: lyceums (theoretical, university-oriented), technical schools, vocational schools; for the purposes of this paper, only the distinction between theoretical and technical/vocational schools is considered;

- two indicators of student persistence: the retention of students in the same degree programme in the year 2 with over 39 ECTS (European Credit Transfer System) credits (\%) and the percentage of students graduating within the prescribed duration of degree programmes; both indicators express how a degree programme promotes and favours student learning;

- the employment rate 1 year after graduation was analysed as an indicator of how degree programmes can prepare a student for the labour market. 
The source of the data and clarifications regarding them are shown in Table 4.

Table 4 - Sources of data

\begin{tabular}{|c|c|c|c|}
\hline Data & Source & $\begin{array}{l}\text { Website } \\
\text { (last access on } 8 / 10 / 2018 \text { ) }\end{array}$ & Further information \\
\hline $\begin{array}{l}\text { Composition of } \\
\text { CEV }\end{array}$ & $\begin{array}{l}\text { Periodic } \\
\text { accreditation report } \\
\text { CINECA teachers } \\
\text { database }\end{array}$ & $\begin{array}{l}\text { http://www.anvur.it } \\
\text { http://cercauniversita.cineca.it/ }\end{array}$ & \\
\hline $\begin{array}{l}\text { Outcome of the } \\
\text { accreditation } \\
\text { procedure and } \\
\text { scores: } \\
\text { Characteristics } \\
\text { of degree } \\
\text { programmes }\end{array}$ & $\begin{array}{l}\text { Periodic } \\
\text { accreditation report }\end{array}$ & http://www.anvur.it & \\
\hline $\begin{array}{l}\text { Secondary } \\
\text { school final } \\
\text { grade and } \\
\text { school type }\end{array}$ & $\begin{array}{l}\text { Student database, } \\
\text { Ministry of } \\
\text { Education, } \\
\text { Universities and } \\
\text { Research }\end{array}$ & $\underline{\text { http://anagrafe.miur.it }}$ & \\
\hline $\begin{array}{l}\text { Student } \\
\text { retention } \\
\text { indicators }\end{array}$ & $\begin{array}{l}\text { Upon the authors' } \\
\text { request to ANVUR }\end{array}$ & --- & $\begin{array}{l}\text { The academic year 2012- } \\
2013 \text { was chosen as a } \\
\text { reference. } \\
\text { The retention of students } \\
\text { in the same degree } \\
\text { programme in the year } 2 \\
\text { with over } 39 \text { ECTS } \\
\text { (European Credit Transfer } \\
\text { System) credits (\%) and } \\
\text { the percentage of } \\
\text { graduates within the } \\
\text { prescribed duration of } \\
\text { degree programmes }\end{array}$ \\
\hline $\begin{array}{l}\text { Employment } \\
\text { rates }\end{array}$ & $\begin{array}{l}\text { Almalaurea. As } \\
\text { shown in the } \\
\text { standard description } \\
\text { document of each } \\
\text { degree programme } \\
\text { required by } \\
\text { ministerial } \\
\text { procedures }\end{array}$ & https://www.universitaly.it/ & $\begin{array}{l}\text { The Almalaurea survey } \\
\text { for the year } 2013 \text { has been } \\
\text { used. }\end{array}$ \\
\hline
\end{tabular}

The use of this data set has a few limits. The analysis was carried out in 173 degree programmes which do not ensure representatively of all degree programmes in Italy. Table 5, 6, 7 show respectively the distribution of degree programmes in relation to ERC sector, geographical area and whether the university is private or public. 
Table 5: ERC Sector of degree programme

\begin{tabular}{lrr}
\hline ERC Sector & Degrees & \% \\
\hline LS & 41 & $22 \%$ \\
\hline PE & 50 & $27 \%$ \\
\hline SH & 94 & $51 \%$ \\
\hline Total & 185 & $100 \%$ \\
\hline
\end{tabular}

Table 6: Location of institution of origin of degree programme

\begin{tabular}{lrr}
\hline Location & Degrees & \% \\
\hline Northern Italy & 73 & $39 \%$ \\
\hline Central Italy & 27 & $15 \%$ \\
\hline Southern Italy & 85 & $46 \%$ \\
\hline Total & 185 & $100 \%$ \\
\hline
\end{tabular}

Table 7: Public/private nature of institution of origin of degree programme

\begin{tabular}{lrr}
\hline Nature of institution & Degrees & \% \\
\hline Private & 43 & $23 \%$ \\
\hline Public & 142 & $77 \%$ \\
\hline Total & 185 & $100 \%$ \\
\hline
\end{tabular}

Secondly, the indicators used in this paper can be subject to criticism and limitations because they do not fully represent the characteristics of a degree programme. It is important to highlight that the data refer to a degree programme and not to individual students. The relevance of the dimensions analysed in relation university-level studies (in particular the characteristics of incoming students, student retention and employability) is discussed extensively in the literature, by way of example see Trow (1973), Tinto (2006), and Marginson (2016).

Obviously, if microdata (i.e. data referring to students such as cultural capital and social status) were to be employed, the analysis could be expanded further. Similarly, 
research intensity could be considered to verify whether and how the presence of more productive researchers influences the outcome of accreditation procedures.

However, the main aim of the article is to discuss the robustness of accreditation systems and therefore an approach to data analysis at the level of degree programme with a focus on the educational aspects is considered appropriate.

In order to answer to the research questions the 15 quality standards have been grouped into two categories 1 (A, excellent practice; $\mathrm{B}$, approved) and $0(\mathrm{C}$, accepted with recommendation; $\mathrm{D}$, not approved because of major critical issues) and then a multivariate logistic regression model was applied considering the quality standards (one model for each standard) as the response variable, the characteristics of the degree programmes - ERC Sector (PE, SH, LS), Bachelor's/Master's/single-cycle degree, geographical area (North/Centre/South), the public or private nature of the university as explanatory variables (control), and the input characteristics of students (secondary school final grade and percentage of lyceum students) as predictors of performance indicators (retention, employment).

The same model has been applied to the overall evaluation, also dichotomised in 1 (Fully Satisfactory, Satisfactory) and 0 (Conditional, Not Accredited). The results can be found in the following section.

\section{Results}

Table 8 shows the results of the multivariate logistic regression for all standards and for the overall evaluation. 
Table 8-Multivariate logistic regression models (coefficients and standard errors)

\begin{tabular}{|c|c|c|c|c|c|c|c|c|c|c|c|c|c|c|c|c|c|}
\hline VARIABLES & AQ5.A.1 & AQ5.A.2 & AQ5A.3 & AQ5.B.1 & AQ5.B.2 & AQ5.B.3 & AQ5.B.4 & AQ5.C.1 & AQ5.C.2 & AQ5.C.3 & AQ5.C.4 & AQ5.D.1 & AQ5.D.2 & AQ5.D.3 & AQ5.E.1 & AQ5.E.2 & Overall \\
\hline \multirow[t]{2}{*}{ ERC LS } & $-1.704 * *$ & $2.333^{* * * *}$ & 0.123 & -0.547 & 0.267 & -0.746 & $-1.428 * * *$ & -1.061 & -0.244 & -1.083 & -0.396 & -0.0511 & 0.678 & -0.259 & -1.264 & -1.123 & $-1.525^{* *}$ \\
\hline & $(0.860)$ & $(0.658)$ & $(0.545)$ & $(0.561)$ & $(0.719)$ & $(0.557)$ & $(0.525)$ & $(0.727)$ & $(0.568)$ & $(0.658)$ & $(0.591)$ & $(0.608)$ & $(0.745)$ & $(0.672)$ & $(0.759)$ & $(1.360)$ & $(0.640)$ \\
\hline \multirow[t]{2}{*}{ ERC SH } & -0.805 & $-1.389 * *$ & 0.179 & 0.378 & -0.116 & 0.264 & -0.733 & -0.761 & -0.124 & -0.573 & -0.397 & -0.154 & -0.0761 & -0.394 & -0.318 & 0.149 & -0.279 \\
\hline & $(0.788)$ & $(0.595)$ & $(0.466)$ & $(0.506)$ & $(0.568)$ & $(0.509)$ & $(0.458)$ & $(0.610)$ & $(0.483)$ & $(0.580)$ & $(0.504)$ & $(0.511)$ & $(0.552)$ & $(0.559)$ & $(0.709)$ & $(1.254)$ & $(0.463)$ \\
\hline \multirow[t]{2}{*}{ Master Degree's } & -1.811 & -0.00541 & -0.258 & 0.417 & -0.211 & -0.830 & -0.543 & 0.321 & -0.594 & 0.523 & 0.294 & 0.397 & 0.105 & 0.820 & 0.433 & -2.244 & 0.356 \\
\hline & $(0.991)$ & $(0.603)$ & $(0.609)$ & $(0.622)$ & $(0.732)$ & $(0.641)$ & $(0.558)$ & $(0.714)$ & $(0.614)$ & $(0.619)$ & $(0.587)$ & $(0.635)$ & $(0.636)$ & $(0.667)$ & $(0.821)$ & $(1.596)$ & $(0.679)$ \\
\hline \multirow[t]{2}{*}{ Bachelor's } & -0.286 & 0.248 & -0.0620 & 0.173 & 0.717 & -0.535 & -0.693 & 0.124 & -0.343 & $1.450^{* *}$ & 0.681 & 0.535 & 1.271 & 0.882 & 0.388 & 0.00332 & 1.112 \\
\hline & $(1.018)$ & $(0.661)$ & $(0.662)$ & $(0.631)$ & $(0.734)$ & $(0.707)$ & $(0.613)$ & $(0.719)$ & $(0.659)$ & $(0.695)$ & $(0.619)$ & $(0.701)$ & $(0.708)$ & $(0.689)$ & $(0.869)$ & $(1.405)$ & $(0.761)$ \\
\hline \multirow[t]{2}{*}{ South Area } & $-3.001 * * *$ & -0.669 & 0.134 & -0.261 & -0.773 & $-1.533 * *$ & 0.0348 & -1.005 & $-1.246 * *$ & -0.656 & $-1.770 * * *$ & 0.380 & -1.000 & 0.277 & $1.811^{-* * *}$ & -0.437 & 0.0810 \\
\hline & $(0.786)$ & $(0.620)$ & $(0.562)$ & $(0.568)$ & $(0.620)$ & $(0.599)$ & $(0.573)$ & $(0.676)$ & $(0.592)$ & $(0.598)$ & $(0.632)$ & $(0.662)$ & $(0.699)$ & $(0.661)$ & $(0.660)$ & $(1.093)$ & $(0.733)$ \\
\hline \multirow[t]{2}{*}{ North Area } & 0.0143 & 0.596 & 0.689 & $1.198 * * *$ & 0.494 & -0.0599 & -0.285 & -0.463 & 0.618 & 0.567 & 0.504 & $1.535^{* * *}$ & 0.156 & 0.120 & 0.186 & 1.821 & 0.772 \\
\hline & $(0.636)$ & $(0.436)$ & $(0.418)$ & $(0.452)$ & $(0.504)$ & $(0.466)$ & $(0.423)$ & $(0.558)$ & $(0.463)$ & $(0.495)$ & $(0.443)$ & $(0.472)$ & $(0.550)$ & $(0.513)$ & $(0.569)$ & $(1.371)$ & $(0.445)$ \\
\hline \multirow[t]{2}{*}{ Private University } & -0.364 & -0.624 & -0.742 & -0.289 & -0.996 & -0.919 & -0.273 & -1.160 & -0.342 & $-1.768 * * *$ & 0.299 & $2.638^{-} * *$ & -0.143 & -0.687 & $1.527^{* * * *}$ & $-2.602 * *$ & -1.227 \\
\hline & $(0.591)$ & $(0.495)$ & $(0.460)$ & $(0.505)$ & $(0.609)$ & $(0.478)$ & $(0.508)$ & $(0.628)$ & $(0.534)$ & $(0.611)$ & $(0.561)$ & $(0.594)$ & $(0.602)$ & $(0.583)$ & $(0.582)$ & $(1.062)$ & $(0.652)$ \\
\hline \multirow[t]{2}{*}{ Retention } & 0.00617 & $0.0230^{* *}$ & 0.00829 & -0.00888 & 0.00726 & -0.0138 & 0.00633 & $0.0440^{* * * *}$ & -0.0212 & -0.00754 & $0.0368^{* * * *}$ & -0.0138 & $0.0313^{* * *}$ & -0.00931 & 0.00677 & -0.0355 & 0.0129 \\
\hline & $(0.0147)$ & $(0.0110)$ & $(0.0101)$ & $(0.0105)$ & $(0.0130)$ & $(0.0104)$ & $(0.00985)$ & $(0.0147)$ & $(0.0110)$ & $(0.0117)$ & $(0.0117)$ & $(0.0114)$ & $(0.0142)$ & $(0.0126)$ & $(0.0134)$ & $(0.0249)$ & $(0.0115)$ \\
\hline \multirow[t]{2}{*}{$\begin{array}{l}\text { Employment rate } 1 \text { year } \\
\text { after graduation }\end{array}$} & $3.619 * * *$ & 1.316 & 1.003 & -0.0648 & -0.0779 & 0.475 & 0.259 & 1.772 & 1.041 & 0.195 & -0.0865 & 0.465 & 2.322 & $2.596 * *$ & $3.048^{* * * *}$ & 4.810 & \begin{tabular}{|l|}
-0.0441 \\
\end{tabular} \\
\hline & $(1.296)$ & $(0.855)$ & $(0.770)$ & $(0.0883)$ & $(0.0997)$ & $(0.851)$ & $(0.880)$ & $(1.200)$ & $(0.961)$ & $(0.997)$ & $(0.140)$ & $(0.845)$ & $(1.271)$ & $(1.146)$ & $(1.087)$ & $(2.536)$ & $(0.0990)$ \\
\hline \multirow[t]{2}{*}{$\begin{array}{l}\text { Students graduating within } \\
\text { the prescribed duration of a } \\
\text { degree programme }\end{array}$} & $-2.976^{* * *}$ & -1.142 & -0.869 & 0.0640 & 0.414 & -0.315 & 0.240 & $3.171 * *$ & 0.235 & $3.476^{* *}$ & 1.513 & -0.343 & -0.769 & -0.983 & $2.540^{* * *}$ & 0.454 & -0.361 \\
\hline & $(1.034)$ & $(0.688)$ & $(0.615)$ & $(0.119)$ & $(1.461)$ & $(0.701)$ & $(1.172)$ & $(1.551)$ & $(1.245)$ & $(1.429)$ & $(1.308)$ & $(0.680)$ & $(1.564)$ & $(1.435)$ & $(0.875)$ & $(2.587)$ & (1.266) \\
\hline \multirow[t]{2}{*}{ Secondary school final grade } & 3.722 & 1.832 & 1.153 & $5.810^{* * *}$ & $4.661 * *$ & 0.672 & 0.725 & $6.494 * * *$ & $3.822 * *$ & $4.841 * *$ & $7.504 * * *$ & $6.059 * * *$ & $4.320 * *$ & 2.133 & -1.566 & 6.147 & $7.866^{* * *}$ \\
\hline & $(2.857)$ & $(1.801)$ & $(1.675)$ & $(2.028)$ & $(2.324)$ & $(1.681)$ & $(1.545)$ & $(2.494)$ & $(1.788)$ & $(2.003)$ & $(2.011)$ & $(1.921)$ & $(2.113)$ & $(1.995)$ & $(2.221)$ & $(5.037)$ & $(\mathbf{1 . 8 5 5 )}$ \\
\hline \multirow[t]{2}{*}{ Secondary school (lyceum) } & -0.837 & -1.151 & 0.290 & 0.252 & 1.796 & -0.695 & -2.682 & 0.591 & -1.176 & 1.150 & -1.463 & 0.164 & -2.046 & 0.728 & $4.103 * *$ & 2.455 & -3.091 \\
\hline & $(1.853)$ & $(1.495)$ & $(1.374)$ & $(1.414)$ & $(1.563)$ & $(1.527)$ & $(1.419)$ & $(1.766)$ & $(1.492)$ & $(1.582)$ & $(1.481)$ & $(1.563)$ & $(1.787)$ & $(1.611)$ & $(1.774)$ & $(2.909)$ & $(1.581)$ \\
\hline \multirow[t]{2}{*}{ Constant } & $3.785 * *$ & 1.022 & -0.0678 & -0.814 & -1.437 & $3.179 * *$ & 2.740 & 0.127 & 1.606 & -2.877 & 0.725 & -0.784 & 2.250 & -0.00884 & 0.0871 & 1.035 & -1.694 \\
\hline & $(1.922)$ & $(1.329)$ & $(1.239)$ & $(1.272)$ & $(1.537)$ & $(1.409)$ & $(1.415)$ & $(1.652)$ & $(1.501)$ & $(1.583)$ & $(1.407)$ & $(1.372)$ & $(1.785)$ & $(1.638)$ & $(1.642)$ & $(3.170)$ & (1.510) \\
\hline & 170 & $1 / 8$ & 170 & 11 & 170 & 14 & . & 178 & 178 & 178 & 173 & 178 & 173 & 173 & 173 & 173 & 173 \\
\hline Pseudo R Square & 0.349 & 0.241 & 0.0881 & 0.152 & 0.150 & 0.103 & 0.0941 & 0.185 & 0.115 & 0.186 & 0.180 & 0.270 & 0.163 & 0.109 & 0.279 & 0.368 & 0.202 \\
\hline
\end{tabular}

Standard errors in parentheses

*** $\mathrm{p}<0.01, * * \mathrm{p}<0.05$ 
The last column of table 8 shows the estimated model for the overall evaluation. The disciplinary characteristics of the degree programme and the secondary school final grade significantly influence the probability of a degree programme to obtain a Satisfactory overall evaluation.

The two negative coefficients in relation to the ERC sector show that the accreditation system rewards degree programmes in certain disciplinary areas compared to others. In particular, Life Sciences programmes are less likely to receive a positive evaluation than Physical Sciences and Engineering, which is the reference category (degree programmes in Social Sciences and Humanities do not differ significantly from Physical Sciences and Engineering).

The data show that the characteristics of the incoming students affect the overall assessment of the CEVs. In particular, the degree courses that attract students with the best performance in terms of final secondary school grade have better results; however, the data on the type of school of origin (lyceum or other) shows that this holds true regardless of the type of the secondary school.

When examining the first three indicators (AQ5.A.1, AQ5.A.2, AQ5.A.3), which show how updated a degree programme is, it can be noticed that ERC macro area has a significant impact in determining the evaluation of the CEVs (indicators AQ5.A.1, AQ5.A.2). According to CEVs, degree programmes in some ERC areas perform better consults than courses in other areas. As regards the indicator AQ5.A.1

(Representativeness of the social parties consulted), the data show that CEVs have verified that the ability to organise consultations with the social partners is greater in degree programmes that are not in southern Italy, that have good results in terms of employment of graduates and that have a high number of students not graduating within 
the prescribed duration of a degree programme (this could be linked to the number of working students).

The second set of indicators concerns the design of a degree programme (AQ5.B.1, AQ5.B.2, AQ5.B.3, AQ5.B.4). Secondary school final grades are positively related to AQ5.B.1 and AQ5.B.2 indicators. The fact that a degree programme is positioned in Northern Italy is positively linked to the ability of ascertaining entry-level required knowledge (AQ5.B.1), whereas degree programmes in Southern Italy are significantly negatively related to consistency between teaching and learning results expected by degree programme (AQ5.B.3). AQ5.B.4 indicator is negatively affected by belonging to Life Sciences ERC area.

The third set of indicators (AQ5.C.1, AQ5.C.2, AQ5.C.3, AQ5.C.4) concerns the self-assessment capacity of a degree programme and presents significant implications for each disciplinary area. The ability to attract students with higher secondary school final grades significantly impacts on the positive evaluation of CEVS.

The degree programmes based in the South of Italy have the lowest selfassessment performances (significant test for the indicators AQ5.C.2 and AQ5.C.4) as well as degree programmes with higher retention rate (significant test for indicators AQ5.C.1 e AQ5.C.4) and degree programmes with higher number of students graduating within the prescribed duration of a degree programme (significant test for indicators AQ5.C.1 e AQ5.C.3).

The fourth set of indicators (AQ5.D.1, AQ5.D.2, AQ5.D.3) focuses on student satisfaction surveys. The degree programmes with the highest employment rate are the ones that perform best in the CEV evaluation (indicators AQ5.D.1, AQ5.D.2). Degree programmes in Northern Italy and in public universities publicise the results of student surveys more widely (AQ5.D.1). The degree programmes with best employment 
prospects are those that are most likely to receive the requests and observations of the students with consistent actions (AQ5.D.3).

The fifth set of indicators (AQ5.E.1, AQ5.E.2) concerns employment opportunities. Degree programmes with a better employment rate are more successful (only AQ5.E.1). Degree programmes in Southern Italy and in which students graduate within the prescribed duration of a degree programme (only AQ5.E.1) and degree programmes in private universities (both AQ5.E.1 and AQ5.E.2) have worse results. Reading the results on the rows (i.e. the impact of the variables on the indicators), with reference to the 16 individual indicators and the overall indicator, we can observe that:

- Life Sciences programmes has four significant coefficients with a minus sign;

- The South of Italy has five significant coefficients with a minus sign

- $\quad$ Private universities have four significant coefficients with a minus sign

- Retention has four significant coefficients, wherof three with a minus sign

- Employment rate has three significant coefficients with a plus sign

- Students graduating within the prescribed duration of a degree programme have four significant coefficients with a variable sign according to the indicator;

- $\quad$ secondary school final grade has nine significant coefficients with a plus sign;

This confirms that, all other things being equal, the quality of incoming students (measured in terms of secondary school final grade) has a very significant impact onthe evaluations of accreditation, i.e. CEVs reward the degree programmes that attract the best students. The employment rate 1 year after graduation is also positive impact, even if less extensive. 
On the other hand, degree programmes belonging the ERC area of Life Sciences, in Southern Italy and in private universities receive significantly negative evaluations by CEVS.

The variables Retention and Students graduating within the prescribed duration of a degree programme have different effects on different indicators.

\section{Discussion and Conclusion}

The analysis based on multivariate logistic regression models shows how it is possible to deal with the issue of the limits of accreditation and QA systems with an evidence-based approach instead of a purely anecdotal approach.

It is possible to compare the results of accreditation and quality assurance procedures with the characteristics of degree programmes and students. From a methodological point of view, this may help evaluation agencies and universities obtain evidence-based elements to discuss the progress of the accreditation system and verify if there is room for improvement. This is a concrete chance to rethink and improve accreditation and QA systems by acknowledging the different meanings that an evaluation exercise can acquire within organisations.

There are two reasons why this possibility is valuable, given that the effectiveness of accreditation systems is not universally acknowledged: first of all, it highlights and possibly validates the objections to the accreditation systems; secondly, and even more importantly, they represent a tool to identify possible weaknesses of accreditation systems to address. 
For example, the analysis carried out on AVA shows that the degree programmes in the ERC PE area, excluding any other consideration regarding the quality of the students or the characteristics of the degree programmes, have obtained better ratings. The links between the outcomes of the accreditation process and the disciplinary specialisation of degree programmes raises the question of whether or not disciplinebased accreditation models, such as the model under examination, are valid. As we have seen, this issue is widely discussed in the literature (Canninng, 2005; Lomas 2007; Haapakorpi, 2011). Questioning this link has advantages both because it allows assessment agencies to verify any disciplinary bias of accreditation systems and because it provides the possibility of a debate about the increased reliability of discipline-based accreditation systems. Again, the results could lead to a reflection on the multidisciplinary background of CEVs, given also the strong disciplinary connotation of CEV chairs as illustrated in Table 2.

In Higher Education it is well known that disciplines have a role in mediating and interpreting the introduction of managerial tools, i.e. instruments that typically try to get people to do things they might not do otherwise (Schneider \& Ingram 1990). Recent studies show how learning outcomes (which were employed in compliance with the AVA model) not only encounter various levels of resistance but also assume meanings and functions that vary across the disciplinary areas where they are employed (Bleiklie et al. 2017; Michelsen et al. 2017).

Through evidence-based analyses, it is possibile to overcome the opposition between supporters and detractors and to refine the systems of accreditation and quality assurance.

Besides methodological issues, this paper provides another contribution. This quantitative analysis can actually provide observations on the factors that result in best 
results in the accreditation process in Italy. These observations, however, are clearly in line with the limits that the literature attributes to accreditation systems.

This second contribution, however, has only an exploratory character as already explained in the Data and methods section. In full awareness of the limitations of this study, the results of our analysis show that more positive results in the accreditation procedure for Italian degree programmes are overall associated with the quality of incoming students and the ERC sector of degree programmes.

As already explained, the analysis of the individual indicators shows that the presence of students with a higher secondary school final grade is by far the factor that is most strongly connected with higher CEV evaluations. A positive relation is also found in the employment rate one year after graduation.

The significance of the secondary school final grade in determining the outcome of the evaluation reveals an input orientation inasmuch as that the accreditation system risks replicating the quality evaluation received by the students, thus confirming the choices of the best graduates.

The strong connection of some factors inherent to the nature of the degree programme (e.g. geographical position of the university, belonging to specific ERC sectors, being a public university) and the simultaneous weak connection with factors regarding the performance of the degree programmes (retention and students graduating within the prescribed duration of a degree programme) raises the question whether the accreditation system rewards degree programmes with certain structural or input characteristics or those that manage to obtain better results in teaching processes. The presence of a positive connection of three indicators with the employment rate can be interpreted as an element in contrast to this analysis (a good graduate rate is a performance of the degree programme) or as a tendency to reward the degree courses that are more 
oriented to the labour market and therefore a confirmation that the CEVs reward a particular type of degree courses, which can attract the best students, located in Northern Italy and involving business-oriented disciplines.

The research conducted on the difficulties of NPM-based evaluation systems highlights that evaluation systems generally tend to favour (i.e. give better evaluations to) the public services that can more easily be framed in a business perspective (Pollitt and Bouckaert 2004; Noordegraaf and Abma 2003). It is not surprising that the degree programmes that are naturally more prone to interact with the corporate sector and that have first implemented accreditation systems enjoy an advantage in terms of evaluation.

On the basis of the classification of Jeliazkova and Westerheijen (2002) the Italian system is still stuck in the early stages (the first and the second stages in particular) and may have difficulties in promoting innovation and a culture of quality. In this sense, the adoption of AVA seems to be affected by the previous experiences of quality assurance in Italy, which mainly focused on the verification of teaching inputs (Turri 2014).

As explained in Section 3, ANVUR has launched a review of the AVA system and, on the basis of this review, new visits have been conducted since 2018 . One of the new features is a stronger link between the outcomes of the QA process and the performance of a degree programme through the consideration of student career indicators. On the basis of the results of this analysis, this increased focus on aspects such as student persistence could go in the right direction, which may help to better balance the accreditation system, thus mitigating the tendency to reward degree programmes in certain subject areas and degree courses that attract better students. More generally, the use of evidence-based analyses such as the one proposed in this study can help verify the differences between old and new exercises and establish the effects of the changes on the evaluation of CEVs. 


\section{Acknowledgements}

We would like to thank the anonymous reviewers for their helpful comments on earlier versions of the paper and, in particular, editor Hugo Horta for his advice. 


\section{References}

ANVUR, (2014). Indicazioni operative alle commissioni di esperti della valutazione per l'accreditamento periodico delle sedi e dei corsi di studio.

ANVUR, (2017). Linee guida per l'accreditamento periodico delle Sedi e dei corsi di studio universitari. Available at http://www.anvur.it/attivita/ava/accreditamento-periodico/lineeguida-per-laccreditamento-periodico/

Becher, T. (1989). Academic tribes and territories: Intellectual enquiry and the cultures of disciplines. Stony Stratford/Ballmoor, Society for Research into Higher Education, SRHE and Open University Press.

Behn, R. D. (2003). Why measure performance? Different purposes require different measures. Public Administration Review, 63(5), 586-606.

Bleiklie, I., Frølich, N., Sweetman, R., \& Henkel, M. (2017). Academic institutions, ambiguity and learning outcomes as management tools. European Journal of Education, 52(1), 68-79.

Canning, J. (2005). Disciplinarity: A barrier to Quality Assurance? The UK experience of area studies. Quality in Higher Education, 11(1), 37-46.

Capano, G., Regini, M., \& Turri, M. (2016). Changing governance in Universities: Italian Higher Education in comparative perspective. London: Palgrave-MacMillan.

Cardoso, S., Rosa, J.M. \& Stensaker, B. (2016). Why is quality in higher education not achieved? The view of academics, Assessment \& Evaluation in Higher Education, 41(6), 950-965.

Cartwright, M. J. (2007). The rhetoric and reality of "Quality" n Higher Education. An investigation into staff perceptions of quality in post 1992 universities. Quality Assurance in Education, 15 (3), 287-301.

Cheng, N. S. (2015). A comparison of compliance and aspirational accreditation models: Recounting a university's experience with both a Taiwanese and an American accreditation body. Higher Education, 70(6), 1017-1032.

Clark, R. E. (1983). Reconsidering research on learning from media. Review of Educational Research, 53(4), 445-459.

Cret, B. (2011). Accreditations as local management tools. Higher Education, 61(4), 415429.

Deem, R. (1998). 'New managerialism' and Higher Education: The management of performances and cultures in universities in the United Kingdom. International Studies in Sociology of Education, 8(1), 47-70.

Diefenbach, T. (2009). New Public Management in public sector organizations: The dark sides of managerialistic 'enlightenment'. Public administration, 87(4), 892-909.

DiMaggio, P., \& Powell, W. W. (1983). The Iron Cage Revisited: Collective rationality and institutional isomorphism in organizational fields. American Sociological Review, 48(2), $147-160$.

Erichsen, H. (1999). The challenges of a European Higher Education space". In Bologna Forum. http://www.eees.es/pdf/challenges.pdf. 
Ferlie, E., Musselin, C., \& Andresani, G. (2008). The steering of Higher Education Systems: A Public Management perspective. Higher Education, 56(3), 325.

Flood, J. T., \& Roberts, J. (2017). The evolving nature of Higher Education accreditation: Legal considerations for institutional research leaders. New Directions for Institutional Research, 2016(172), 73-84.

Frølich N., \& Caspersen J. (2015). Institutional Governance Structures. In: Huisman J., de Boer H., Dill D.D., Souto-Otero M. (Ed.), The Palgrave International Handbook of Higher Education Policy and Governance (pp. 379-397). London: Palgrave Macmillan.

Haakstad, J. (2001). Accreditation: The new Quality Assurance formula? Some reflections as Norway is about to reform its Quality Assurance System. Quality in Higher Education, $7(1), 77-82$.

Haapakorpi, A. (2011). Quality Assurance processes in Finnish Universities: Direct and indirect outcomes and organisational conditions. Quality in Higher Education, 17(1), 6981.

Harvey, L. (2005). A history and critique of quality evaluation in the UK. Quality Assurance in Education, 13(4), 263-276.

Harvey, L. (2006). Impact of quality assurance: Overview of a discussion between representatives of external quality assurance agencies. Quality in Higher Education, 12(3), 287-290.

Harvey, L. (2016). Lessons learned from two decades of quality in Higher Education. https://www.qualityresearchinternational.com/Harvey2016Lessons.pdf.

Harvey, L., \& Newton, J. (2004). Transforming quality evaluation. Quality in Higher Education, 10(2), 149-165.

Harvey, L., \& Newton, J. (2007). Transforming quality evaluation: Moving on. In: Westerheijden D.F., Stensaker B., Rosa M.J. (Ed.) Quality Assurance In Higher Education. Higher Education Dynamics, vol 20 (pp. 225-245). Dordrech: Springer.

Harvey, L., \& Williams, J. (2010). Editorial: Fifteen years of Quality in Higher Education: Part two." Quality in Higher Education, 16(2), 81-113.

Hood, C. (1995). The 'New Public Management' in the 1980s: Variations on a theme. Accounting, Organizations and Society, 20(2-3), 93-109.

Huisman, J., \& Westerheijden, D. F. (2010). Bologna and Quality Assurance: Progress made or pulling the wrong cart? Quality in Higher Education, 16(1), 63-66.

Jeliazkova, M., \& Westerheijden, D. F. (2002). Systemic adaptation to a changing environment: Towards a next generation of Quality Assurance models. Higher Education, 44(3-4), 433-448.

Leiber, T., Stensaker, B. \& Harvey, L. (2015). Impact evaluation of Quality Assurance in Higher Education: Methodology and causal designs. Quality in Higher Education, 21(3), 288-311.

Lomas, L. (2007). Are students customers? Perceptions of academic staff. Quality in Higher Education, 13(1), 31-44.

Marginson S. (2016). The worldwide trend to high participation higher education: dynamics of social stratification in inclusive. Higher Education 72(4), 413-434. 
Meek, V. L., \& Davies, D. (2009). Policy dynamics in Higher Education and Research: Concepts and observations. In Meek, V. L., Teichler, U., \& Kearney (Ed.), Higher Education, Research and Innovation: Changing Dynamics. (pp. 41-84) M. L. INCHERKassel.

Meyer, J. W., Rowan, B., Powell, W. W., \& DiMaggio, P. J. (1991). The New Institutionalism in organizational analysis (Vol. 17). Chicago: University of Chicago Press.

Michelsen, S., Vabø, A., Kvilhaugsvik, H., \& Kvam, E. (2017). Higher Education learning outcomes and their ambiguous relationship to disciplines and professions. European Journal of Education, 52(1), 56-67.

Morley, L. (2003). Quality and power in Higher Education. McGraw-Hill Education (UK).

Neave, G., \& Van Vught, F. A. (1991). The changing relationship between government and Higher Education in Western Europe. Oxford: Pergamon Press.

Newton, J. (2013). Is Quality Assurance leading to enhancement? In How does quality assurance make a difference? A selection of papers from the 7th European Quality Assurance Forum (pp. 8-14).

Noman Z. (2008). Performance budgeting in the United Kingdom. OECD Journal on Budgeting 8, 1-15.

Noordegraaf, M., \& Abma, T. (2003). Management by measurement? Public management practices amidst ambiguity. Public Administration, 81(4), 853-871.

Perry, J. L., Engbers, T. A., \& Jun, S. Y. (2009). Back to the future? Performance- Related Pay, empirical research, and the perils of persistence. Public Administration Review, 69(1), $39-51$.

Pollitt, C. (2009). Bureaucracies remember, post-bureaucratic organizations forget? Public Administration, 87(2), 198-218.

Pollitt, C., \& Bouckaert, G. (2004). Public Management Reform: A comparative analysis. Oxford: Oxford University Press.

Ratcliff, J. L. (2003). Dynamic and communicative aspects of quality assurance. Quality in Higher Education, 9(2), 117-131.

Rebora, G., \& Turri, M. (2011). Critical factors in the use of evaluation in Italian Universities. Higher Education, 61(5), 531-544.

Rhoades, G., \& Sporn, B. (2002). Quality Assurance in Europe and the US: Professional and political economic framing of Higher Education policy. Higher Education, 43(3), 355390.

Rosa M.J., \& Amaral A. (2012) Is There a Bridge Between Quality and Quality Assurance? In: Stensaker B., Välimaa J., Sarrico C.S. (Ed.) Managing Reform in Universities. Issues in Higher Education. (pp. 114-134). London: Palgrave Macmillan.

Schneider, A., \& Ingram, H. (1990). Behavioral assumptions of policy tools. The Journal of Politics, 52(2), 510-529.

Schwarz S., \& Westerheijden D.F. (2004) Accreditation in the Framework of Evaluation Activities: A Comparative Study in the European Higher Education Area. In: Schwarz S., Westerheijden D.F. (Ed.) Accreditation and Evaluation in the European Higher Education Area. Higher Education Dynamics, vol 5 (pp. 1-42). Dordrecht: Springer. 
Shah, M. (2013). The effectiveness of external Quality Audits: A study of Australian Universities. Quality in Higher Education, 19(3), 358-375.

Shah, M., \& Sanford, S. (2013). The impact of external quality audit in a private for-profit tertiary education institution. In Shah, M., \& Nair, C. S External (Ed.), Quality Audit. Has it improved Quality Assurance in universities? Oxford: Chandos Publishing.

Sin, C., Tavares, O., \& Amaral, A. (2017). The impact of programme accreditation on Portuguese Higher Education provision. Assessment \& Evaluation in Higher Education, 42(6), 860-871.

Stensaker, B. (1997). From accountability to opportunity: the role of quality assessments in Norway. Quality in Higher Education, 3(3), 277-284.

Stensaker, B. (2008). Outcomes of Quality Assurance: A discussion of knowledge, methodology and validity". Quality in Higher Education, 14(1), 3-13.

Stensaker, B. (2011). "Accreditation of Higher Education in Europe - Moving towards the US model? Journal of Education Policy, 26(6), 757-769.

Stensaker, B. (2014). European trends in Quality Assurance: New agendas beyond the search for convergence. In Rosa, M. J. \& Amaral, A. (Ed.) Quality Assurance in Higher Education: Contemporary Debates (pp. 135-148). Basingstoke: Palgrave.

Sursock, A. (2000). Towards accreditation schemes for Higher Education in Europe. Interim findings of the project, CRE Association of European Universities, Paris.

Talib, A. A. (2003). The offspring of New Public Management in English Universities: 'Accountability', 'Performance Measurement', 'Goal-Setting'and the Prodigal Child-The RAE. Public Management Review, 5(4), 573-583.

Thomas, I. (2004). Sustainability in tertiary curricula: What is stopping it happening? International Journal of Sustainability in Higher Education, 5(1), 33-47.

Tinto, V. (2006). Research and Practice of Student Retention: What Next? Journal of College Student Retention: Research, Theory \& Practice, 8(1), 1-19.

Trow, M. (1973). Problems in the Transition from Elite to Mass Higher Education. Carnegie Commission on Higher Education. Berkeley: Berkeley Press.

Turri, M. (2014). The new Italian Agency for the Evaluation of the University System (ANVUR): A Need for governance or legitimacy? Quality in Higher Education, 20(1), 6482.

Van de Bovenkamp, H., Vollaard, H., Trappenburg, M., \& Grit, K. (2013). Voice and choice by delegation. Journal of Health Politics, Policy and Law, 38(1), 57-87.

Van der Wende, M. C., \& Westerheijden, D. F. (2001). International aspects of Quality Assurance with a special focus on European Higher Education. Quality in Higher Education, 7(3), 233-245.

Van Dooren, W., Bouckaert G., \& Halligan J. (2010). Performance Management in the Public Sector. London: Routledge.

Van Vught, F. (1988). A New Autonomy in European Higher Education? An exploration and analysis of the strategy of self-regulation in Higher Education governance.

International Journal of Institutional Management in Higher Education, 12(1), 16-26. 
Veiga, A., Rosa, M. J., Dias, D., \& Amaral, A. (2013). Why is it difficult to grasp the impacts of the Portuguese Quality Assurance System? European Journal of Education, 48(3), 454-470.

Vidovich, L. (2002). Quality Assurance in Australian Higher Education: Globalisation and steering at a distance. Higher Education, 43(3), 391-408.

Westerheijden, D, Hulpiau, V and Waetens, K. (2007). From design and implementation to impact of Quality Assurance: An overview of some studies into what impacts improvements. Tertiary Education and Management 13(4), 295-312.

Westerheijden, D.F. (2007) States and Europe and Quality of Higher Education. In: Westerheijden, D.F., Stensaker, B., \& Rosa M.J. (Ed.) Quality Assurance In Higher Education. Higher Education Dynamics, vol 20 (pp. 73-95). Dordrecht: Springer.

Wilkerson, J. R. (2017). Navigating similarities and differences in national and international accreditation standards: A proposed approach using US Agency requirements. Quality Assurance in Education, 25(2), 126-145. 